\title{
COMPARAÇÃO DA PRODUÇÃO DE CONSOANTES FRICATIVAS PÓS-ALVEOLARES PALATALIZADAS E NÃO PALATALIZADAS POR ESTUDANTES BRASILEIROS DE POLONÊS E POR FALANTES NATIVOS
}

\author{
Comparación de la Producción de Consonantes Fricativas Postalveolares \\ Palatalizadas y No Palatalizadas Por Estudiantes Brasileños de Polaco y \\ Por Hablantes Nativos
}

\author{
Ivan Eidt COLLING ${ }^{1}$ \\ Universidade Federal do Paraná \\ ivanchjo@ufpr.br \\ https://orcid.org/0000-0003-4813-4465
}

\begin{abstract}
RESUMO: Neste artigo apresento uma análise da produção de consoantes fricativas não vozeadas pós-alveolares não palatalizadas [ $\left.\int\right]$ e palatalizadas (alvéolo-palatais) [ 6 ] por falantes nativos de polonês e por brasileiros que estudam essa língua. Tais consoantes fazem parte do sistema fonológico do polonês, mas em português - bem como em espanhol, francês, inglês - não são fonemas distintos, motivo pelo qual apresentam um grau de dificuldade considerável no aprendizado por falantes de português. Foram realizadas gravações de palavras contendo aqueles sons fricativos com quatro informantes poloneses e, usando técnicas da fonética acústica, analisaram-se dezessete parâmetros sobre as produções do par de palavras siewca/szewc, constatando-se, em concordância com referências sobre o tema, que a frequência do segundo formantenatransiçãoparaavogalsubsequenteéumainformaçãorelevante na distinção de consoantes fricativas pós-alveolares palatalizadas e não palatalizadas. A análise dessa frequência foi posteriormente realizada sobre os dados dos registros de leituras feitas por quatro estudantes de Letras-Polonês da Universidade Federal do Paraná. Os resultados assim obtidos são comparados com aqueles produzidos pelos falantes nativos. A verificação da frequência de transição é realizada também sobre as produções do par de palavras siekiera/szybkowar. PALAVRAS-CHAVE: Fonética comparada português-polonês; Fonética acústica; Consoantes fricativas pós-alveolares; Fonologia polonesa.
\end{abstract}

\footnotetext{
${ }^{1}$ Membro do grupo de pesquisas Filosofia, Ciência e Tecnologias e coordenador do projeto de extensão Línguas em Diálogo. O presente estudo está baseado no Trabalho de Conclusão do Curso de Graduação em Letras-Polonês, realizado na Universidade Federal do Paraná sob a orientação do Prof. Ms. Eduardo Nadalin e co-orientação da Profa. Dra. Adelaide Hercília Pescatori Silva (v. COLLING, 2014).
} 
RESUMEN: En este artículo presento un análisis de la producción de consonantes fricativas sordas postalveolares no palatalizadas (arqueadas) [ $\int$ ] y palatalizadas (alveolo-palatales) [ 6 ] por hablantes nativos del polaco y por brasileños, estudiantes de esa lengua. Las mencionadas consonantes son parte del sistema fonológico polaco, pero en portugués - y en español - no constituyen fonemas distintos. Por esa razón presentan un considerable nivel de dificultad en el aprendizaje por hablantes del portugués. Han sido realizadas grabaciones de palabras que contienen aquellos sonidos fricativos con cuatro informantes polacos. Utilizándose técnicas de fonética acústica, se analizaron diecisiete parámetros en las producciones del par de palabras siewca/szewc, los cuales permitieron constatarse, en acuerdo con las referencias sobre el tema, que la frecuencia del segundo formante en la transición para la vogal subsiguiente es una información relevante para distinguir las consonantes postalveolares palatalizadas y no palatalizadas. Posteriormente el análisis de esa frecuencia fue hecho sobre los datos registrados de lecturas realizadas por cuatro estudiantes de Letras-Polaco de la Universidad Federal de Paraná. Los resultados obtenidos son comparados con aquellos producidos por los hablantes nativos. Un análisis de la frecuencia de transición fue también hecho sobre las producciones del par de palabras siekiera/szybkowar. PALABRAS-CLAVE: Fonética comparada portugués-polaco; Fonética acústica; Consonantes fricativas postalveolares; Fonología de la lengua polaca.

STRESZCZENIE: W niniejszym artykule przedstawiam analizę produkcji spółgłosek szczelinowych bezdźwięcznych zadziąsłowych (niepalatalnych)[J]idziąsłowo-podniebiennych(środkowojęzykowych, palatalnych) [6] przez rodzimych użytkowników języka polskiego i przez brazylijskich studentów tego języka. Takie spółgłoski należą do systemu fonologicznego języka polskiego, ale w języku portugalskim - tak jak w hiszpańskim, francuskim, angielskim - nie są różnymi fonemami i z tego powodu stanowią znaczny poziom trudności dla portugalskojęzycznych osób uczących się języka polskiego. Dokonano nagrań słów zawierających wyżej wymienione szczelinowe dźwięki z czterema polskimi informatorami i, używając technik fonetyki akustycznej, przeanalizowano siedemnaście parametrów dotyczących pary słów siewca/szewc, konstatując, zgodnie z literaturą na ten temat, że frekwencja drugiego formantu podczas przejścia do następnej samogłoski jest ważną informacją dla rozróżnienia spółgłosek palatalnych i niepalatalnych. Analizę tej frekwencji zrealizowano następnie na bazie nagrań wymowy czterech brazylijskich studentów Polonistyki Uniwersytetu Federalnego Parany. Wyniki takiej 
analizy zostały później porównane $\mathrm{z}$ tymi produkowanymi przez rodzimych użytkowników języka polskiego. Dalsza analiza została przeprowadzona na bazie produkcji pary słów siekiera/szybkowar. SLOWA KLUCZOWE: Fonetyka porównawcza portugalsko-polska; Fonetyka akustyczna; Spółgłoski szczelinowe zadziąsłowe i dziąsłowopodniebienne; Fonologia polska.

\section{INTRODUÇÃO}

Há em polonês quatro consoantes fricativas que apresentam uma peculiar diferença com relação a consoantes a elas assemelhadas em português. Trata-se das consoantes fricativas pós-alveolares vozeadas / 3, z / e não vozeadas $/ \int, 6 /$. A segunda consoante em cada grupo difere-se da primeira por ser palatalizada. No sistema fonológico português não se encontram / z / e / 6 /, ao passo que em polonês podem-se identificar pares mínimos, relacionados portanto a significados diferentes, baseados unicamente na maior ou menor proximidade do dorso da língua ao palato durante a produção dessas consoantes fricativas: kasza (sêmola) / Kasia (nome próprio feminino afetivo correspondente a Katarzyna), kosz (cesta) / koś (verbo kosić - ceifar, segar, cortar - conjugado na segunda pessoa do singular do modo imperativo), ryż (arroz) / ryś (lince).

Ainda que de fato a quantidade desses pares seja pequena, conforme afirma Jassem (1995) - de modo que poucas situações de dubiedade ocorram em função do desvio na produção desses sons -, não somente evitar ambiguidades deve ser a meta dos aprendizes ao desenvolverem sua pronúncia na língua estrangeira. Os sons da fala "constituem o primeiro aspecto que chama a nossa atenção quando nos deparamos com uma língua qualquer ou com um dialeto de nossa própria língua, diferente daquele que falamos" (SILVA, 2007, p. 5). Essa ligação íntima chega a se manifestar em alguns idiomas pelo uso da mesma palavra para identificar tanto o órgão muscular situado na boca e na faringe como o sistema abstrato de signos (por exemplo, língua em português, lengua em espanhol, langue em francês, język em polonês). John Wells (1989, p. 2526), ex-presidente da Associação Fonética Internacional, em uma reflexão sobre a boa pronúncia do esperanto, identifica quatro critérios; permito-me adaptar três deles para o caso da pronúncia do polonês: a) critério prático: uma boa pronúncia permite adequada compreensão entre um estrangeiro que aprendeu polonês e um falante nativo dessa língua ou entre dois estrangeiros que aprenderam polonês; b) critério linguístico: devese procurar espelhar o sistema fonológico do polonês, com boa distinção de sons que produzem pares mínimos; c) critério sociológico: a pronúncia não causa estranhamento 
entre os membros da comunidade de fala do polonês (isso não significa uma tentativa de adesão total ao modelo de um "falante nativo ideal", porém a produção dos diversos segmentos, seu encadeamento e também a prosódia estão dentro de faixas aceitáveis; tais faixas são mais largas em comunidades linguísticas mais habituadas a ouvirem pessoas de diversas origens praticando os idiomas, como o francês, o alemão, o inglês, o russo, o espanhol, o português, o esperanto, e mais estreitas em outras, como o polonês). Assim, o esforço para distinguir os sons palatalizados dos não palatalizados atende com mais ênfase os critérios linguístico e sociológico.

No presente trabalho, faz-se uma investigação, utilizando-se técnicas da fonética acústica, da produção das consoantes fricativas pós-alveolares não vozeadas não palatalizadas e palatalizadas por falantes nativos de polonês no par de palavras szewc e siewca. Os resultados são comparados com as análises das produções do mesmo par de palavras por quatro informantes brasileiros, aprendizes de polonês. Na sequência, procedimento semelhante é aplicado às produções do par szybkowar e siekiera. Inicialmente, no entanto, faz-se uma apresentação das consoantes fricativas pós-alveolares em polonês, incluindo-se também as africadas.

\section{CONSOANTES FRICATIVAS PÓS-ALVEOLARES EM POLONÊS}

As consoantes aqui estudadas correspondem aos segmentos iniciais de szewc

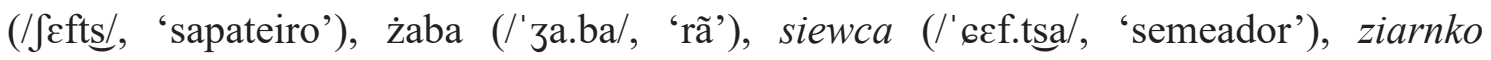
(/'zarn.ko/, 'grão', 'grãozinho'), ou seja, / $\int, 3,6$, z /, e recebem neste trabalho respectivamente as denominações pós-alveolar não palatalizada não vozeada (ou surda), pós-alveolar não palatalizada vozeada (ou sonora), pós-alveolar palatalizada não vozeada, pós-alveolar palatalizada vozeada.

É importante registrar que se encontram também outras nomenclaturas: palatoalveolar (para pós-alveolar) e alvéolo-palatal (para pós-alveolar palatalizada), presentes em Ladefoged (2001, p. 143). Inicialmente, o autor distingue os sons retroflexos / s , z / dos palato-alveolares / $\int, 3 /$ mencionando ainda denominações alternativas:

- pós-alveolar apical, equivalente a retroflexa (a constrição no trato vocal é feita com a parte de baixo da ponta da língua; o dorso da língua toma o aspecto de uma concha, e graças a essa concavidade forma-se uma câmara de volume considerável entre o dorso da língua e o palato), e

- pós-alveolar laminar, sinônimo de palato-alveolar (produzida com a parte de cima da ponta da língua e convexidade no dorso da língua, que forma uma espécie de abóbada). 
Na sequência Ladefoged (2001) comenta:

\begin{abstract}
A tabela do IPA coloca palato-alveolares na coluna de pós-alveolares. Em uma seção intitulada "outros símbolos" também menciona alvéolopalatais e inclui os símbolos [6, ъ ]. Esses símbolos são usados para as fricativas não vozeada e vozeada do polonês e do chinês. São semelhantes a $\left[\int, 3\right]$, mas implicam uma considerável elevação da parte da frente da língua. Elas também são produzidas na região pósalveolar. (p. 143-144, tradução minha).
\end{abstract}

Já Haman (2002) apresenta uma argumentação em favor da classificação das consoantes pós-alveolares do polonês como retroflexas, a partir da constatação de que elas diferem significativamente daquelas costumeiramente representadas por $/ \int, 3 /$, em função do papel desempenhado pela ponta da língua em sua produção, bem como da percepção do som pelos ouvintes e acrescenta que tal proposição está presente em publicações anteriores, como LADEFOGED e MADDIESON (1996). De fato, em 2003 Ladefoged (p. 151-152) considera essas consoantes como fricativas retroflexas, utilizando, em lugar de / J , z/, os símbolos / s, z /. No mesmo ano, Jassem (p. 103-104), em uma apresentação dos fonemas do polonês, não faz menção à retroflexão, utiliza os símbolos / $\int, 3,6$, z / e denomina os dois primeiros 'alveolares laminares'.

$\mathrm{Na}$ nomenclatura em polonês utilizam-se para $/ \int, 3 /$ os termos dziąsłowa ("alveolar") ou zadziąsłowa ("pós-alveolar") em contraste com palatalna, dziąsłowopodniebienna ("alvéolo-palatal”) ou środkowojęzykowa ("no meio da língua", mostrando que para sua produção deve-se provocar um estreitamento do canal de passagem do ar na boca, elevando-se a língua de modo que uma parte central de seu dorso fique bem próxima do palato) para / 6 , ъ / (MACIOŁEK; TAMBOR, 2012, p. 33). Na descrição desta última articulação em língua inglesa encontra-se palatal (soft), logo com ideia de 'suave', 'branda' ou 'mole' (MADELSKA; SCHWARTZ, 2010, p. 14).

Cumpre salientar que a distinção palatalização/não palatalização está presente também nas consoantes africadas, de modo que são oito os sons a chamar a atenção dos professores e aprendizes, conforme sumarizado no quadro 1, em que apresento os parâmetros articulatórios e as representações fonéticas e ortográficas. Saliento que este trabalho se limita às consoantes fricativas não vozeadas $/ \int, 6 /$. 
QUADRO 1 - SONS FRICATIVOS E AFRICADOS PÓS-ALVEOLARES EM POLONÊS.

\begin{tabular}{|c|c|c|c|c|c|c|}
\hline \multicolumn{3}{|c|}{ Parâmetros articulatórios } & \multicolumn{3}{|c|}{ Representações fonéticas } & \multirow{2}{*}{$\begin{array}{l}\text { Representações } \\
\text { ortográficas(3) }\end{array}$} \\
\hline Modo & Vozeamento & Palatalização & IPA & $(1)$ & $(2)$ & \\
\hline \multirow{4}{*}{ Fricativa } & \multirow[b]{2}{*}{ - } & - & {$\left[\int\right]$} & {$\left[\int\right]$} & {$[\check{s}]$} & $\mathrm{sz}, \dot{\mathrm{z}}, \mathrm{rz}$ \\
\hline & & + & [6] & [ç] & [ś ] & ś, si \\
\hline & \multirow{2}{*}{+} & - & {$[3]$} & {$[3]$} & {$[\check{z}$ ] } & $\dot{\mathrm{z}}, \mathrm{rz}$ \\
\hline & & + & [z] & {$[z]$} & [ź ] & ź, zi \\
\hline \multirow{4}{*}{ Africada } & \multirow{2}{*}{ - } & - & [t] & {$[\mathrm{E}]$} & [ č ] & $\mathrm{cz}$ \\
\hline & & + & [ t6 ] & [ Æૃ̧ ] & [ć ] & ć, ci \\
\hline & \multirow{2}{*}{+} & - & {$[\mathrm{d} 3]$} & {$[\widehat{\mathrm{dz}}]$} & {$[\check{3}]$} & $\mathrm{dz}, \mathrm{drz}$ \\
\hline & & + & {$[\mathrm{d} z \mathrm{z}]$} & {$[\widehat{\mathrm{dz}}]$} & [3́ ] & dź, dzi \\
\hline
\end{tabular}

1) usado por DLUGOSZ (2009); 2) usado por MACIOŁEK e TAMBOR (2012) e por BARTNICKA e SATKIEWICZ (2007); 3) na coluna "Representações ortográficas" estão diferentes representações para os sons em questão; por exemplo, na palavra ryż ('arroz') a última consoante é grafada como ż, porém ocorre desvozeamento em função de sua posição em final de palavra.

FONTES: além daquelas mencionadas nas notas: IPA (2020). Cumpre ainda mencionar que, dentre as obras consultadas ao longo do trabalho, utilizam os símbolos do IPA: ASSAF (2007) e MADELSKA; SCHWARTZ (2010).

\section{DEFINIÇÃO DO CORPUS E COLETA DE DADOS}

Foram realizadas gravações de um conjunto de palavras cujo segmento inicial é o som / $\int$ / e de outro conjunto com o segmento inicial / 6 /, procurando evitar palavras que tenham sons nasais. Aproveitando minha estada na cidade de Poznań, Polônia, em setembro de 2014, fiz gravações também de palavras que contêm os segmentos vozeados / 3 / e / z /. Além disso, de maneira a desviar a atenção dos informantes a respeito do foco da investigação, foram incluídos distratores, ou seja, palavras que não contêm os sons fricativos em estudo. No total, são seis palavras em cada grupo (segmento inicial $/ \int /, / 3 /, / 6 / \mathrm{ou} / \mathrm{z} /$ ) e 44 distratores. Todas pertencem à classe gramatical dos substantivos e foram inseridas na sentença-veículo "Ewa wymawia teraz" ("Ewa pronuncia __ agora"). Teraz ("agora") foi incluído para evitar que a palavra-alvo ficasse em posição final de sentença, situação em que há uma tendência ao apagamento dos sons, e foi escolhida por iniciar pela oclusiva / $\mathrm{t} /$, que contribui para isolar acusticamente o final da palavra-alvo.

Uma vez definidos o corpus, os distratores e a sentença-veículo, foram preparadas 
fichas, cada uma com uma sentença, que foram embaralhadas e mostradas, uma após a outra, ao(à) informante no momento da gravação. Dessa forma, tem-se algum controle sobre a velocidade em que as sentenças são lidas, evitando-se que o informante se apresse para concluir sua tarefa. Ao todo foram feitas, com cada informante, seis séries de gravações de todas as sentenças-veículo, embaralhando-se as fichas ao final de cada série (a fim de se evitar a influência da memorização de uma sequência de palavrasalvo a serem lidas). Procurou-se observar que os informantes mantivessem o mesmo tom durante as gravações, a fim de que mudanças de entonação não viessem a interferir na comparação entre diferentes emissões. Quando observava que a pessoa estava se pondo nervosa, ou se por algum motivo ocorria alguma mudança na emissão da voz, deixava de lado a ficha, reconduzindo-a mais adiante na mesma série; por vezes interrompi a gravação para retomá-la logo em seguida. Cinco séries foram utilizadas, ficando a sexta como uma reserva para o caso de alguma das anteriores não se prestar ao estudo por algum problema técnico na gravação, som muito baixo, ruído no ambiente no momento da coleta ou por presença de dados de difícil análise ou inconsistentes.

As gravações foram feitas utilizando-se dois gravadores digitais Panasonic RRUS550 (um dos aparelhos funcionou como reserva). As análises espectrais foram realizadas em 2014, utilizando-se o programa Praat na versão 5.4.02 (BOERSMA; WEENINK, 2014); já as medições referentes ao segundo formante na transição para a vogal subsequente foram refeitas para o presente artigo, com uma delimitação mais criteriosa da quantidade de formantes e da frequência máxima dos formantes (conforme apresento mais adiante), tendo-se para isso utilizado a versão 6.1.16 do programa Praat (BOERSMA; WEENINK, 2020).

Foram entrevistados dois informantes do sexo masculino e duas informantes do sexo feminino, falantes nativos de polonês com idades entre 45 e 60 anos. Todos têm ainda em comum o fato de serem esperantistas, que foram contatados durante o evento ARKONES (Artaj Konfrontoj en Esperanto "Confrontos Artísticos em Esperanto", tradicional evento anual que reúne cerca de duas centenas de esperantistas em Poznań). São aqui identificados como P1M, P2F, P3F e P4M, em que "P" indica "polonês/polonesa" e M/F, "masculino" / "feminino". Ao identificador é acrescido o número da série a que se refere: P3F4 corresponde à quarta série de registros realizados com a informante P3F. P1M nasceu e reside em Varsóvia, sendo que durante parte de sua vida viveu em região próxima a Varsóvia $(20 \mathrm{~km})$; nível de escolaridade: superior incompleto. P2F nasceu e até o momento residiu somente em Varsóvia; nível de escolaridade: superior. P3F nasceu e reside em Gdańsk, tendo residido também em Toruń e em Czarna Woda; nível de 
escolaridade: superior. P4M nasceu e reside em Poznań, tendo residido durante dez anos em Varsóvia; nível de escolaridade: superior incompleto.

Os informantes brasileiros são todos estudantes do Curso de Letras Polonês na Universidade Federal do Paraná, com idades entre 18 e 50 anos; a característica comum é terem concluído pelo menos $480 \mathrm{~h}$ de estudo formal de língua polonesa na Universidade. Foram utilizados os identificadores B1F, B2F, B3M e B4M, em que "B" indica "brasileiro/ brasileira" e M/F, "masculino" / "feminino". Níveis de escolaridade: B2F e B4M: superior incompleto, B3M: superior, B1F: pós-graduação.

\section{PARÂMETROS PARA ANÁLISE DOS SONS FRICATIVOS PÓS-ALVEOLA- RES}

As consoantes fricativas se caracterizam por serem ondas aperiódicas, mostrandose no espectrograma como um sinal semelhante a um "chuvisco", o que pode ser observado na fig. 1, em que apresento os sinais referentes à produção da sentença veiculando a palavra szufla ('pá'). Na figura, tem-se três ocorrências da fricativa vozeada [ v ], e posteriormente as não vozeadas $\left[\int\right]$, [ f ] e [ s ]; pode-se observar que as amplitudes das formas de onda das consoantes fricativas se mostram reduzidas quando comparadas, por exemplo, com aquelas das vogais. Além disso, a barra de sonoridade, presente nos sinais referentes à vozeada [ v ], está sensivelmente enfraquecida durante a emissão das não vozeadas, bem como durante a oclusão para a produção de $[\mathrm{t}]$.

Diferentes conformações do trato vocal implicam mudanças nos parâmetros físicos da onda resultante, que por sua vez causam modificação na percepção pelo ouvinte/ interlocutor. Uma primeira abordagem para a distinção dos sons fricativos pode ser a faixa de frequências em que tem início o ruído: enquanto para / s / o ruído é percebido somente por volta de $5 \mathrm{kHz}$, para / $\int$ / já se percebe o sinal em $3 \mathrm{kHz}$ (SILVA, 2007, p. 69). No entanto, não se percebe tal diferenciação entre os sons $/ \int / \mathrm{e} / \mathrm{6} /$, dada a proximidade dos espectros de seus sinais. Outros parâmetros que têm sido utilizados para a distinção entre as fricativas são baseados em análises estatísticas ou na frequência do segundo formante na transição para a vogal subsequente, conforme detalhado nos itens a seguir. 


\section{FIGURA 1 - REGISTRO P4M1: "EWA WYMAWIA SZUFLA TERAZ”.}

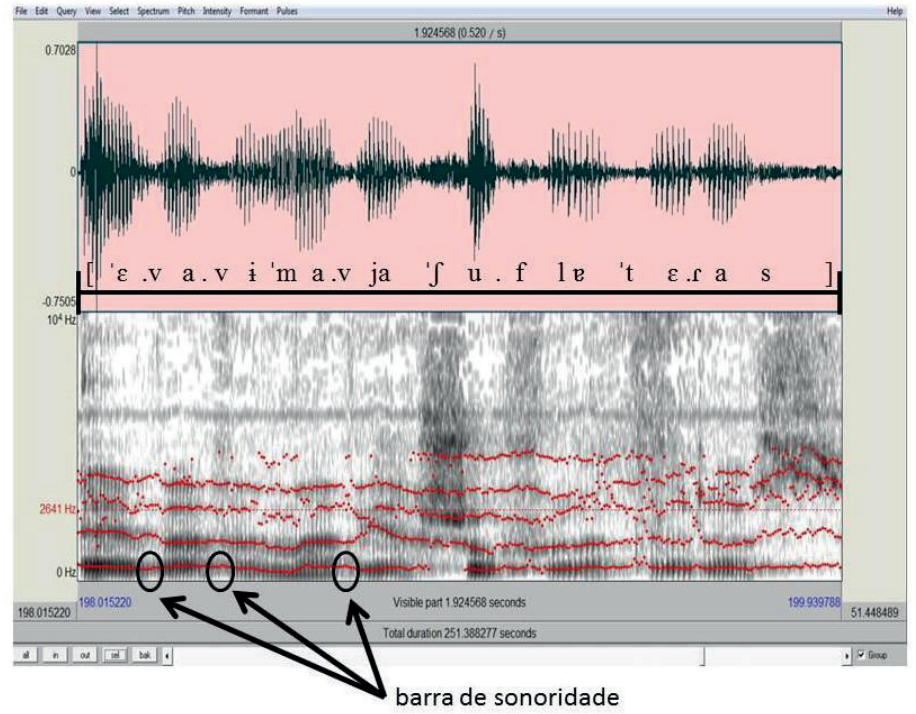

FONTE: O autor.

\section{Análises estatísticas das distribuições de frequências}

Os sons fricativos se apresentam em uma ampla faixa de frequências e são aperiódicos, ou seja, não se concentram em regiões discretas. Por esse motivo, é muitas vezes conveniente realizar um tratamento estatístico dos dados no domínio da frequência, ou seja, uma representação na qual se tem, no eixo das abscissas, não mais os dados de tempo, mas de frequência. O programa Praat possui ferramenta para a apresentação dos dados no domínio da frequência via Transformada Rápida de Fourier (FFT); gera-se assim um novo ‘objeto' que pode ser armazenado para futura utilização e sobre o qual se podem realizar diferentes análises estatísticas, permitindo que se investiguem padrões de distribuição das frequências peculiares a cada tipo de som fricativo em estudo. Em geral, a atenção é dirigida aos parâmetros centroide, desvio padrão, assimetria e curtose, que são momentos centrais da distribuição de frequências do ruído fricativo (BARBOSA, 2011, p. 31-32; OLIVEIRA, 2011, p. 34-36; JASSEM, 1995). Apresento como exemplo a palavra siewca na emissão em P3F1 (fig. 2), da qual foi destacada somente a fricativa [6 ] inicial, tendo-se considerado na análise somente a parte central do segmento, correspondente a $80 \%$ de sua duração (fig. 3).

Nas expressões do centroide e dos momentos espectrais, usados para o cálculo do 
desvio padrão, da curtose e da simetria, é utilizado o expoente $p$ (apresento as expressões no Apêndice A). Há liberdade no programa Praat para que o usuário trabalhe com diferentes valores desse expoente, bem como possibilidade de se efetuar filtragem da faixa de frequência, com filtros passa-faixa e rejeita-faixa. Lançando mão de toda essa gama de opções, ao todo foram testadas dezesseis combinações desses fatores sobre as produções de szewc e siewca pelos falantes nativos, buscando-se encontrar algum parâmetro que pudesse diferenciar os dados acústicos de $\left[\int\right]$ e de [6] ("dados filtrados" refere-se à filtragem pela qual foram considerados somente os sinais na faixa de $1,5 \mathrm{kHz}$ a $15 \mathrm{kHz}$ ):

- pico espectral;

- centroide:

$$
p=2
$$

$$
p=1,5
$$

- centroide, dados filtrados:

$$
\begin{array}{ll}
p=1,5 ; & p=1 ; \\
p=1,5 ; &
\end{array}
$$

- desvio padrão:

- assimetria:$$
p=1,5
$$$$
p=1 \text {; }
$$

- curtose:

$p=2$;

$p=1,5$

$p=1$;

- $\sqrt[4]{\mu_{4}}$ :

$$
p=2 \text {; }
$$$$
p=1,5 \text {; }
$$$$
p=1 \text {; }
$$

$p=2$

Como mostrado no quadro 2, nenhum dos parâmetros acima foi capaz de discernir com segurança os sons em questão.

FIGURA 2 - REGISTRO P3F1, PALAVRA “SIEWCA”. Está destacada a fricativa inicial.

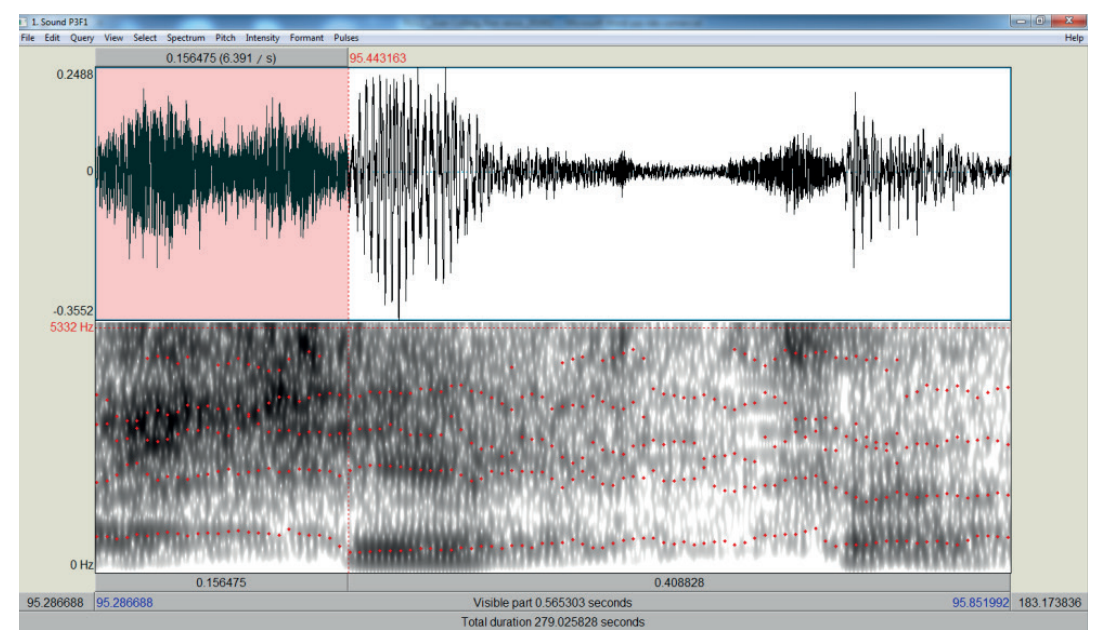

FONTE: $\mathrm{O}$ autor. 
FIGURA 3 - SEGMENTO INICIAL [ 6 ] DE "SIEWCA" (P3F1). Para a análise, em cada extremidade foram desconsiderados $10 \%$ da duração do segmento.

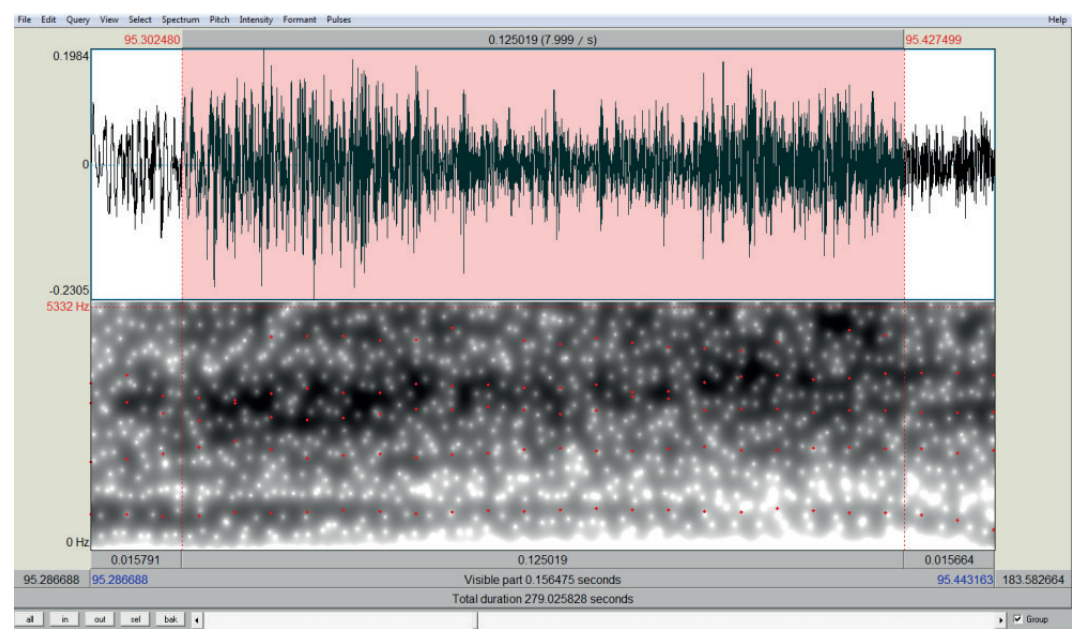

FONTE: O autor.

\section{Segundo formante na transição da fricativa para a vogal subsequente}

Jassem (1995) em uma análise dos dados das fricativas não vozeadas [ f , s , א , , , x ] de três informantes do sexo masculino, havia mostrado serem indistinguíveis os sons $\left[\int, 6\right]$ por meio dos parâmetros centroide, assimetria e curtose. Oliveira (2011), Wagner, Ernestus e Cutler (2006) e Li, Edwards e Beckman (2009) apontam para o estudo do segundo formante (F2) na transição da fricativa para a vogal subsequente como uma pista acústica relevante. A frequência F2 na transição, que neste trabalho denoto por F2 ${ }^{\mathrm{t}}$, está correlacionada ao tamanho da cavidade posterior à constrição no trato vocal, sendo inversamente proporcional a esse tamanho (OLIVEIRA, 2011, p. 36). Tal resultado está embasado na teoria acústica da produção da fala, proposta por Fant em 1960 (SILVA, 2007, p. 72).

Com a análise do segundo formante pode-se ter uma indicação sobre a posição do dorso da língua na transição da consoante fricativa para a vogal subsequente. Se a consoante fricativa for a não palatalizada $\left[\int\right]$, há uma cavidade de volume considerável no trato vocal no início da produção da vogal, o que se refletirá em uma frequência F2 ${ }^{\mathrm{t}}$ de valor inferior àquele que se verifica quando a mesma vogal é produzida em seguida à consoante palatalizada [6 ], pois neste caso há somente um estreito canal para a passagem do ar no trato vocal. Procuro representar na fig. 4 o espectrograma produzido 
nos instantes finais da produção da fricativa não vozeada (a área sombreada representa o ruído fricativo), ilustrando a trajetória dos formantes até atingirem os valores referentes à produção da vogal (que, na prática poderão não se manter "horizontais" como mostra a figura idealizada).

FIGURA 4 - TRANSIÇÃO DA CONSOANTE FRICATIVA NÃO VOZEADA PARA A VOGAL SUBSEQUENTE. Representam-se as trajetórias dos formantes antes de atingirem os valores que se manterão durante a produção da vogal.

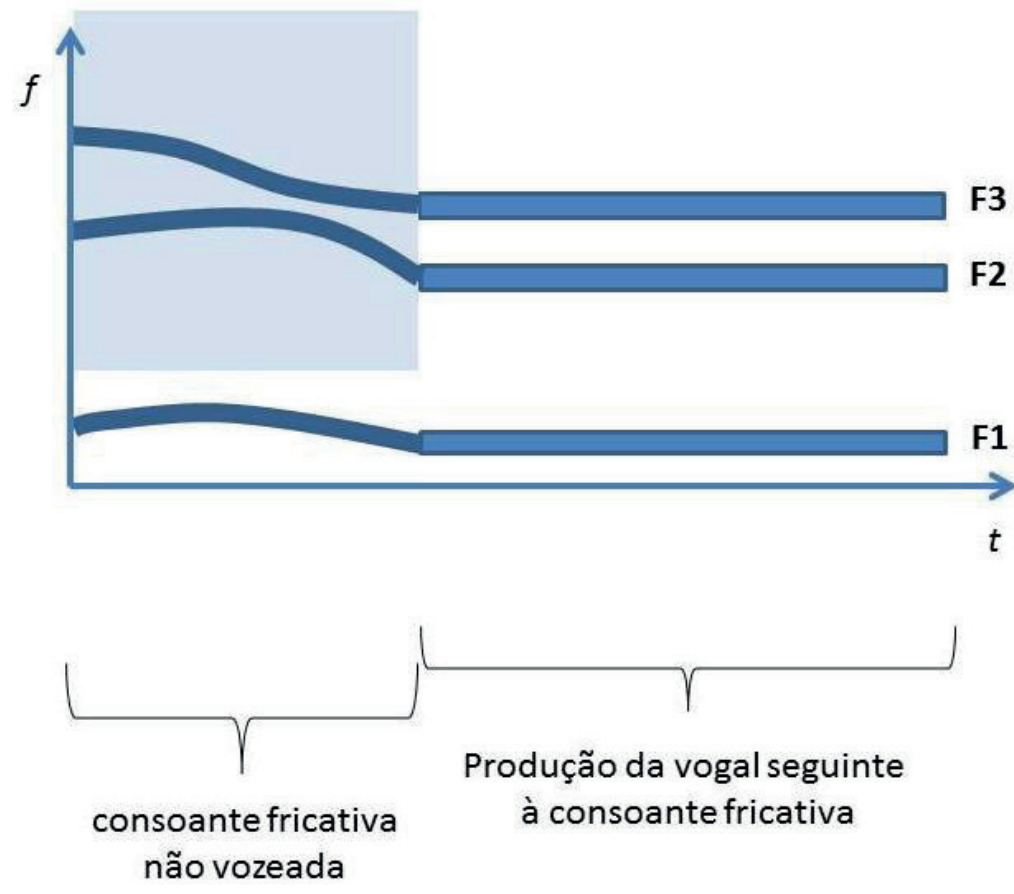

FONTE: O autor.

No final do intervalo de sinal aperiódico que caracteriza a fricativa, observa-se o início da configuração do sinal periódico, correspondente à vogal. Em virtude da possível flutuação de F2 nessa transição, adotou-se como critério tomar o valor da frequência no instante em que ocorre o segundo pico de mesmo sentido (ou o segundo vale, ou a segunda crista) do sinal periódico, como ilustrado na fig. 5, buscando-se assim uma unidade de tratamento nas diversas medições. 


\section{FIGURA 5 - DEFINIÇÃO DO MOMENTO PARA MEDIDA DO SEGUNDO FORMANTE NA TRANSIÇÃO FRICATIVA [ 6 ] - VOGAL [ $\varepsilon$ ] EM SIEWCA (B2F3).}

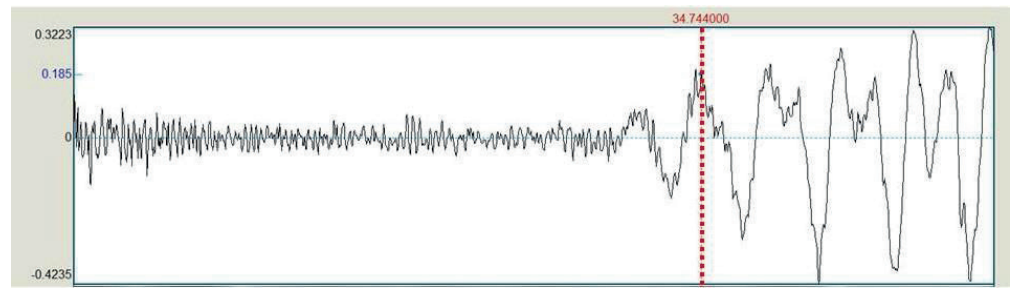

FONTE: O autor.

\section{RESULTADOS OBTIDOS}

\section{Análise dos parâmetros espectrais}

Conforme mencionei anteriormente, foram realizadas seis séries de gravações com cada informante, das quais cinco foram analisadas. O valor numérico de cada parâmetro corresponde à média das três medidas intermediárias obtidas - nesse cálculo foram desconsiderados, portanto, os extremos. A investigação teve início com as produções do par szewc/siewca pelo falante P4M; esse par foi escolhido pela semelhança estrutural entre as duas palavras e pelo fato de se ter a mesma vogal / $\varepsilon$ / após o segmento inicial.

No Apêndice B estão tabelas com os resultados de medições aqui abordados, obtidos por meio do programa Praat, versão 5.4.02. Observa-se que alguns dos parâmetros não se prestam para distinguir os sons produzidos por P4M, como o centroide, cujos valores para [ $\left.\int\right]$ se situam na faixa $[2.778 ; 3.451](\mathrm{Hz})$ e para [ 6$]$ em $[2.383 ; 2.940](\mathrm{Hz})$, ou seja, há uma intersecção na região entre $2.778 \mathrm{~Hz}$ e $2.940 \mathrm{~Hz}$. Mais imbricado se revela o desvio padrão, para o qual a região $[1.361 \mathrm{~Hz} ; 1.563 \mathrm{~Hz}]$ é compartilhada por ambas as fricativas. Essas intersecções estão representadas pelas áreas sombreadas nas figs. 6a e 6b. A assimetria de [6] calculada com $p=2$, por sua vez, está completamente contida na faixa referente a $\left[\int\right]$. Quando, no entanto, se utiliza potência $p=1,5$, esse parâmetro passa a apresentar valores em regiões distintas, com um estreito intervalo de segurança, conforme ilustrado na fig. 7a. Os parâmetros com esse potencial têm suas médias grafadas em negrito nas tabelas B.1 e B.2, com destaque para a curtose calculada com $p=1,5$ (v. fig. 7b); o centroide com $p=1$ mostra-se pouco robusto, em virtude da proximidade entre os valores limítrofes (3.734 e 3.799). 
FIGURA 6 - CENTROIDE (a) E DESVIO PADRÃO (b) REFERENTES ÀS PRODUÇÕES DAS FRICATIVAS EM "SZEWC" E EM "SIEWCA" PELO INFORMANTE P4M. As áreas sombreadas mostram a intersecção entre os conjuntos de valores, evidenciando serem as consoantes indistinguíveis segundo esses parâmetros.

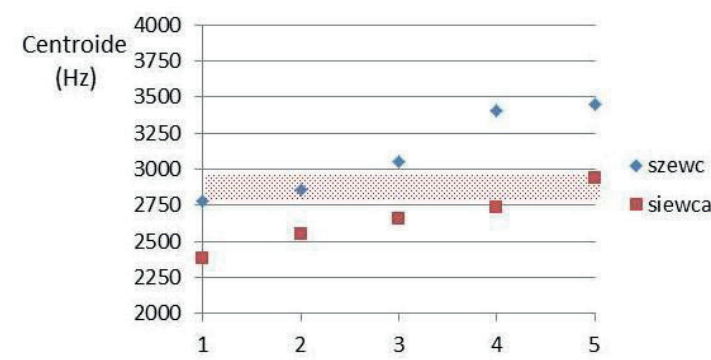

(a)

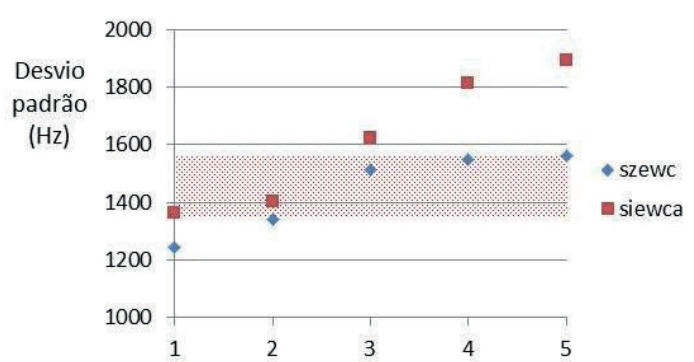

(b)

FONTE: O autor.

FIGURA 7- VALORES DE ASSIMETRIA E DE CURTOSE (AMBOS COM $p=1,5$ ) DAS FRICATIVAS EM "SZEWC" E EM "SIEWCA" PRODUZIDAS PELO INFORMANTE P4M. Esse parâmetro apresenta um potencial para discernir as consoantes. A faixa horizontal demarca o "intervalo de segurança" entre os valores limítrofes.

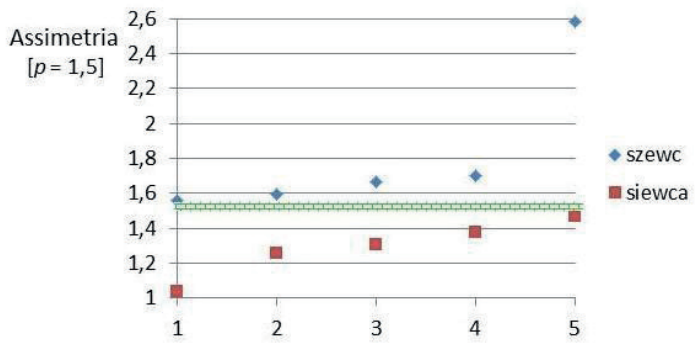

(a)

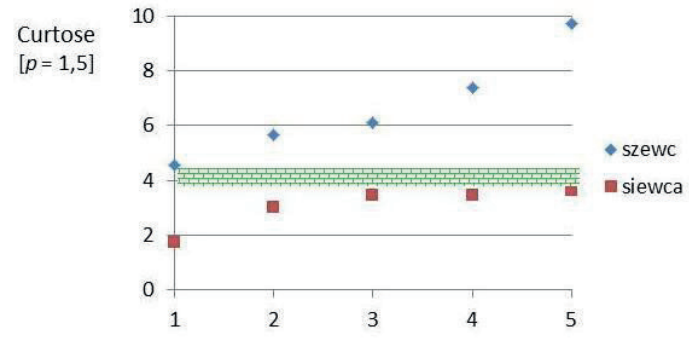

(b)

FONTE: O autor.

Análises semelhantes foram realizadas sobre os dados dos outros falantes nativos de polonês. No entanto, como se pode observar no quadro 2, nenhum dos parâmetros que apresentaram algum potencial para discernir as fricativas produzidas por um dos falantes confirmaram seu desempenho para todos. 
QUADRO 2 - PARÂMETROS QUE PERMITIRAM A DISTINÇÃO DOS SEGMENTOS INICIAIS DE SZEWC E DE SIEWCA NOS DADOS DE PELO MENOS UM DOS INFORMANTES.

\begin{tabular}{|c|c|c|c|c|}
\hline Informante & P1M & P2F & P3F & P4M \\
\hline Centroide & sim & não & não & não \\
\hline Centroide $[p=1,5]$ & $\operatorname{sim}$ & não & sim & não \\
\hline Centroide $[p=1]$ & não & não & sim & sim \\
\hline Centroide $^{\uparrow \uparrow}$ & n.t. & não & sim & n.t. \\
\hline Centroide $^{\uparrow \uparrow}[p=1]$ & não & sim & não & não \\
\hline Assimetria $[p=1,5]$ & não & n.t. & n.t. & sim \\
\hline Curtose & não & não & não & sim \\
\hline Curtose $[p=1,5]$ & não & não & não & sim \\
\hline
\end{tabular}

"Sim" - permite a distinção; "não" - não permite a distinção; "n.t." - não testado. O símbolo $\uparrow \uparrow$ indica que o parâmetro foi calculado sobre os dados filtrados, isto é, considerando-se somente frequências na faixa de $1,5 \mathrm{kHz}$ a $15 \mathrm{kHz}$.

FONTE: O autor.

\section{Análise da frequência do segundo formante na transição para a vogal subsequente}

As análises apresentadas nesta seção foram realizadas por meio do programa Praat, versão 6.1.16, com os seguintes ajustes:

- frequência máxima dos formantes:

- 5,0kHz para P1M, P4M, B3M e B4M;

- $5,5 \mathrm{kHz}$ para P2F, P3F e B1F;

- $6,0 \mathrm{kHz}$ para B2F;

- quantidade de formantes: 5;

- largura da janela: 0,025s;

- faixa dinâmica: $30 \mathrm{~dB}$.

Apresento na tabela 1 os dados referentes ao segundo formante na transição para a vogal subsequente $\left(\mathrm{F}^{\mathrm{t}}\right)$ no contraste entre [ 6 ] em siewca e [ $\left.\int\right]$ em szewc, conforme dados coletados dos falantes poloneses. Da mesma forma como na seção anterior, as médias nas tabelas são feitas retirando-se os valores extremos de cada linha. Denomino "Razão 6 / J" o quociente entre as frequências médias assim obtidas. Os dados acústicos da tabela 1 mostram, como se pode antever a partir da bibliografia consultada, que essa 
razão entre os informantes poloneses é superior à unidade, evidenciando a palatalização em siewca em contraste com a não palatalização em szewc. F2 ${ }^{\mathrm{t}}$ da fricativa [ 6 ] fica na faixa de $21 \%$ a $37 \%$ acima dos valores associados a [ $\left.\int\right]$.

As médias dos resultados de $\mathrm{F}^{\mathrm{t}}$ obtidos entre os estudantes brasileiros (tabela 2) indicam que há um esforço, principalmente de $\mathrm{B} 2 \mathrm{~F}$ e de $\mathrm{B} 3 \mathrm{M}$, para promover a diferenciação entre as consoantes, porém com menor grau do que se observa entre os falantes nativos: para esses dois sujeitos, a Razão $6 / \int$ apresenta-se pouco mais de $10 \%$ acima da unidade. No entanto, somente B3M consegue manter, na série de dados coletados, uma tênue distinção de $24 \mathrm{~Hz}$ entre os dois conjuntos de frequências: o maior valor correspondente a [ $\int$ ] em szewc é $1.981 \mathrm{~Hz}$ e o menor referente a [ 6 ] em siewca é $2.005 \mathrm{~Hz}$ - no caso dos falantes nativos essa distinção sempre foi observada, sendo mais estreita $(125 \mathrm{~Hz})$ nos dados de $\mathrm{P} 2 \mathrm{~F}$.

\section{TABELA 1 - FORMANTE F2 NA TRANSIÇÃO PARA A VOGAL SUBSEQUENTE NA PRODUÇÃO DE [ 6 ] EM SIEWCA E DE [ $\int$ ] EM SZEWC PELOS INFORMANTES POLONESES.}

\begin{tabular}{|c|c|c|c|c|c|c|c|c|}
\hline Sujeito & Cons. & \multicolumn{5}{|c|}{ Registros (Hz) } & $\begin{array}{c}\text { Média } \\
(\mathrm{Hz})\end{array}$ & $\begin{array}{r}\text { Razão } \\
6 / \int\end{array}$ \\
\hline \multirow{2}{*}{$\mathrm{P} 2 \mathrm{~F}$} & [6] & 2.398 & 2.274 & 2.494 & 2.252 & 2.181 & 2.308 & \multirow{2}{*}{1,211} \\
\hline & {$\left[\int\right]$} & 2.014 & 1.856 & 1.846 & 1.681 & 2.056 & 1.906 & \\
\hline \multirow{2}{*}{$\mathrm{P} 3 \mathrm{~F}$} & [6] & 2.267 & 2.251 & 2.260 & 2.255 & 2.356 & 2.261 & \multirow{2}{*}{1,269} \\
\hline & {$\left[\int\right]$} & 1.825 & 1.782 & 1.707 & 1.860 & 1.737 & 1.782 & \\
\hline \multirow{2}{*}{ P1M } & [6] & 1.992 & 1.883 & 1.932 & 2.014 & 2.031 & 1.980 & \multirow{2}{*}{1,318} \\
\hline & {$\left[\int\right]$} & 1.490 & 1.455 & 1.523 & 1.492 & 1.550 & 1.501 & \\
\hline \multirow{2}{*}{ P4M } & [6] & 1.769 & 1.956 & 1.959 & 1.929 & 1.953 & 1.946 & \multirow{2}{*}{1,369} \\
\hline & {$\left[\int\right]$} & 1.430 & 1.543 & 1.401 & 1.355 & 1.435 & 1.422 & \\
\hline
\end{tabular}

FONTE: O autor. 
TABELA 2 - FORMANTE F2 NA TRANSIÇÃO PARA A VOGAL SUBSEQUENTE NA PRODUÇÃO DE [ 6 ] EM SIEWCA E DE [ $\int$ ] EM SZEWC PELOS INFORMANTES BRASILEIROS.

\begin{tabular}{|c|c|c|c|c|c|c|c|c|}
\hline Sujeito & Cons. & \multicolumn{5}{|c|}{ Registros (Hz) } & $\begin{array}{c}\text { Média } \\
(\mathrm{Hz})\end{array}$ & Razão \\
\hline \multirow{2}{*}{$\mathrm{B} 1 \mathrm{~F}$} & [6] & 2.259 & 2.208 & 2.248 & 2.174 & (Obs. 1) & 2.222 & \multirow{2}{*}{1,076} \\
\hline & {$\left[\int\right]$} & 2.030 & 1.994 & 1.953 & 2.213 & 2.175 & 2.066 & \\
\hline \multirow{2}{*}{$\mathrm{B} 2 \mathrm{~F}$} & [6] & 2.712 & 2.652 & 2.594 & 2.502 & 2.246 & 2.583 & \multirow{2}{*}{1,101} \\
\hline & {$\left[\int\right]$} & 2.389 & 2.256 & 2.484 & 2.294 & 2.355 & 2.346 & \\
\hline \multirow{2}{*}{$\mathrm{B} 3 \mathrm{M}$} & [6] & 2.015 & 2.055 & 2.082 & 2.005 & 2.072 & 2.048 & \multirow{2}{*}{1,117} \\
\hline & {$\left[\int\right]$} & 1.981 & 1.917 & 1.790 & 1.795 & 1.788 & 1.834 & \\
\hline \multirow{2}{*}{ B4M } & [6] & 1.813 & 1.577 & 1.900 & 1.677 & 2.041 & 1.797 & \multirow{2}{*}{1,016} \\
\hline & {$\left[\int\right]$} & 1.840 & 1.791 & 1.972 & 1.672 & 1.653 & 1.768 & \\
\hline
\end{tabular}

1) Duas ocorrências dos registros de siewca por B1F não puderam ser utilizadas; optou-se então por calcular a média com base nos quatro registros remanescentes.

2) É notável a estabilidade dos dados fornecidos por B3M para F2 na produção de [ 6 ]: todos os dados estão concentrados em uma faixa com largura de $77 \mathrm{~Hz}$, entre $2.005 \mathrm{~Hz}$ e $2.082 \mathrm{~Hz}$.

FONTE: O autor.

A variação de F2 na transição pode ser vista nas figs. 8 e 9, que representam as formas de onda e os espectrogramas da sentença-veículo respectivamente com siewca e com szewc, produzidas pelo informante P1M. Estão marcadas com elipses as formas de onda referentes às consoantes fricativas e, no espectrograma, a setas indicam as variações de F2, descendente no caso da palatalizada [ 6 ] e ascendente no caso da não palatalizada $\left[\int\right]$. 
FIGURA 8 - SENTENÇA “EWA WYMAWIA SIEWCA TERAZ”, REGISTRO P1M3. A forma de onda da consoante [ 6 ] está marcada pela elipse. A seta indica o movimento descendente de F2 na transição.

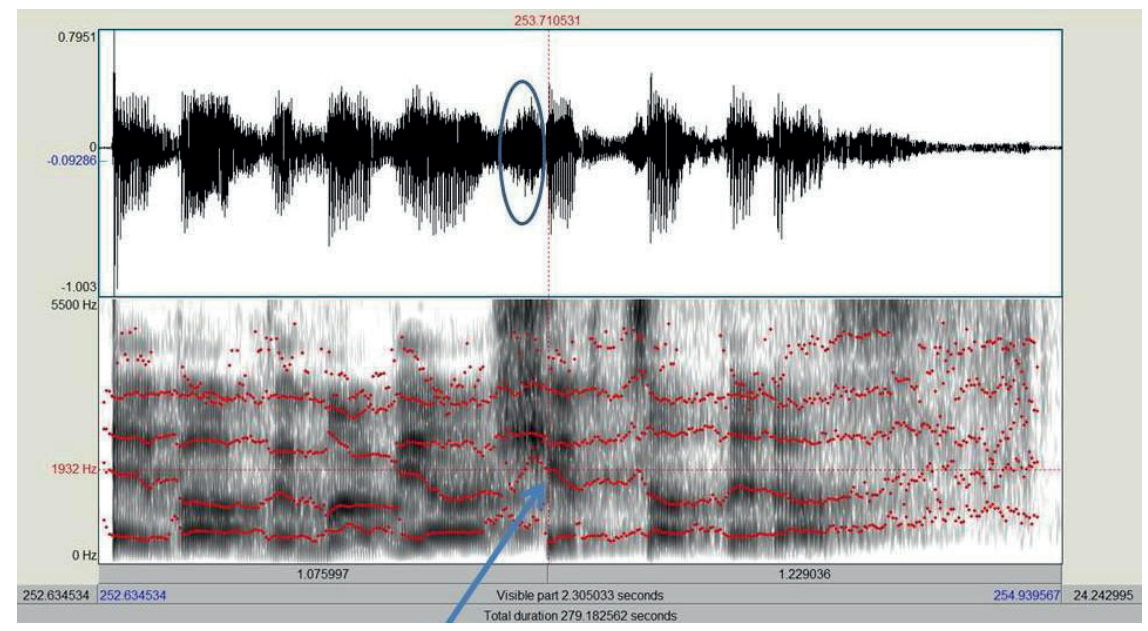

FONTE: O autor.

FIGURA. 9 - SENTENÇA “EWA WYMAWIA SZEWC TERAZ”, REGISTRO P1M3. Na forma de onda, a elipse destaca a ocorrência da fricativa $\left[\int\right]$. No espectrograma, percebe-se movimento ascendente de F2 na transição, indicado pela seta.

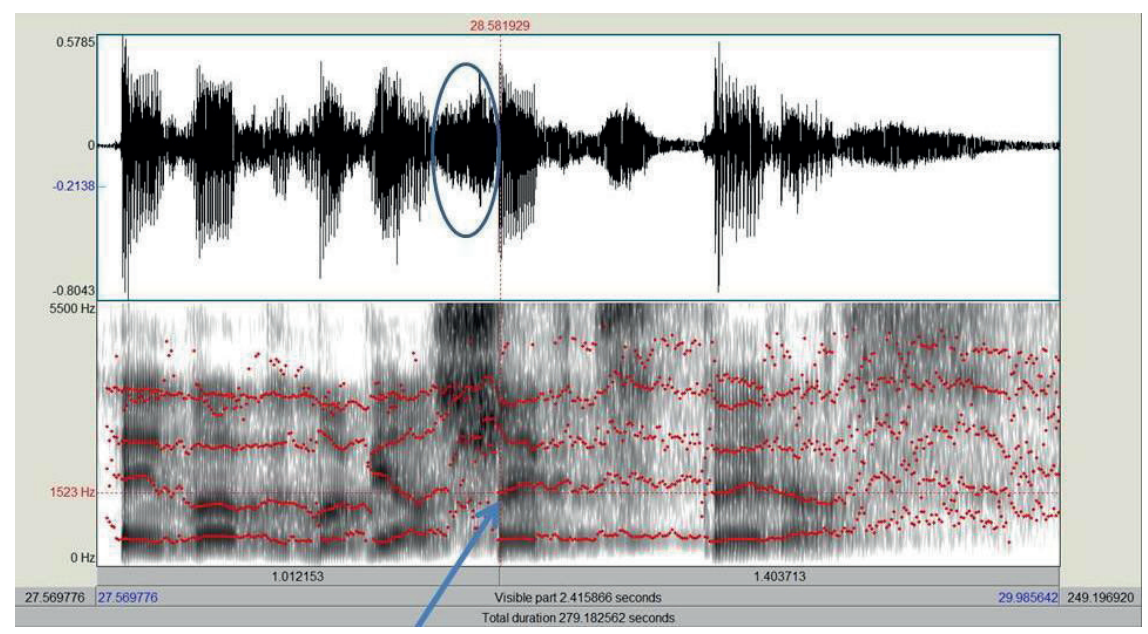

FONTE: O autor. 
Nova análise contrastiva foi realizada, desta vez utilizando-se o par siekiera / szybkowar. Tem-se neste caso palavras trissílabas, em que há uma diminuição da importância relativa dos sons fricativos iniciais em função da presença de mais elementos nas palavras, que facilitam sua compreensão no momento da enunciação. Por outro lado, ocorre uma modificação no ambiente sonoro: enquanto a vogal subsequente em siekiera é a mesma que ocorre em siewca e em szewc ( / ع /, anterior meio-aberta não arredondada; ainda que, em siekiera, pelo fato de ser produzida entre consoantes palatalizadas, a vogal pode ter uma pronúncia mais fechada), em szybkowar tem-se a vogal alta central não arredondada $/ \dot{\mathrm{i}} /$, representada ortograficamente por $y$. Cumpre salientar que são raras em polonês as sequências de sons [ $\left.\int \mathrm{i}\right]$ e [ $\left.6 \dot{1}\right]$, o que se reflete na ortografia: a letra $i$ indica palatalização, de modo que somente em casos excepcionais as regras ortográficas do polonês aceitam a sequência szi (bem como $c z i$ ). Em geral são usadas para palavras estrangeiras e também possuem grafias alternativas: Sziwa/Siwa/Śiwa ('Xiva', deus hindu), szintoizm/sintoizm ('xintoísmo') (cfr. DUBISZ, 2008). Uma vez que o experimento envolve leitura, imaginou-se que a presença de $y$ na palavra induziria a um maior abaixamento do dorso da língua entre os estudantes brasileiros.

Os resultados obtidos com os falantes nativos são apresentados na tabela 3 . Os valores da Razão $6 / \int$ mostram uma redução com relação àqueles da tabela 1 , mas confirmam uma tendência à produção de uma frequência $\mathrm{F} 2^{\mathrm{t}}$ mais elevada em presença da consoante palatalizada. Se por um lado entre os nativos houve intersecção entre as séries de valores para um dos falantes, PM1, cuja Razão $6 / \int$ foi a mais baixa, 12\% acima da unidade, entre os brasileiros (v. tabela 4) somente não se verifica intersecção nos dados de B1F, cuja Razão 6 / $\int$, a mais alta do grupo, situa-se 8,6\% acima da unidade; os outros estudantes fazem pouca ou nenhuma distinção na frequência entre siekiera e szybkowar, tendo-se inclusive um resultado abaixo da unidade. Destaco ainda a dificuldade de medida de F2t nos dados de szybkowar: algumas vezes a vogal [ [ ] é fracamente pronunciada ou praticamente apagada, tanto por nativos como por brasileiros. 
TABELA 3 - FORMANTE F2 NA TRANSIÇÃO PARA A VOGAL SUBSEQUENTE: [ 6 ] EM SIEKIERA / [ $\int$ ] EM SZYBKOWAR, INFORMANTES POLONESES.

\begin{tabular}{|c|c|c|c|c|c|c|c|c|}
\hline Sujeito & Cons. & \multicolumn{5}{|c|}{ Registros (Hz) } & $\begin{array}{c}\text { Média } \\
(\mathrm{Hz})\end{array}$ & $\begin{array}{c}\text { Razão } \\
6 / \int\end{array}$ \\
\hline \multirow{2}{*}{$\mathrm{P} 2 \mathrm{~F}$} & {$[6]$} & 2.324 & 2.319 & 2.396 & 2.370 & 2.453 & 2.363 & \multirow{2}{*}{1,274} \\
\hline & {$\left[\int\right]$} & 1.824 & 1.783 & 1.703 & 2.016 & 1.960 & 1.856 & \\
\hline \multirow{2}{*}{ P3F } & [6] & 2.300 & 2.385 & 2.246 & 2.306 & 2.341 & 2.316 & \multirow{2}{*}{1,186} \\
\hline & {$\left[\int\right]$} & 1.870 & 1.954 & 1.894 & 2.011 & 2.129 & 1.653 & \\
\hline \multirow{2}{*}{$\mathrm{P} 1 \mathrm{M}$} & [6] & 1.994 & 1.878 & 1.938 & 1.935 & 2.044 & 1.956 & \multirow{2}{*}{1,122} \\
\hline & {$\left[\int\right]$} & 1.735 & 1.653 & 1.623 & 1.840 & 1.899 & 1.743 & \\
\hline \multirow{2}{*}{$\mathrm{P} 4 \mathrm{M}$} & [6] & 2.006 & 1.993 & 2.043 & 2.007 & 1.953 & 2.002 & \multirow{2}{*}{1,313} \\
\hline & {$\left[\int\right]$} & 1.498 & 1.530 & 1.566 & 1.448 & 1.547 & 1.525 & \\
\hline
\end{tabular}

FONTE: O autor.

TABELA 4 - FREQUÊNCIA F2 NA TRANSIÇÃO PARA A VOGAL SUBSEQUENTE CONFORME OS DADOS DOS APRENDIZES BRASILEIROS REFERENTES A [ 6 ] EM SIEKIERA E [ $\left.\int\right]$ EM SZYBKOWAR.

\begin{tabular}{|c|c|c|c|c|c|c|c|c|}
\hline Sujeito & Cons. & \multicolumn{5}{|c|}{ Registros (Hz) } & $\begin{array}{l}\text { Média } \\
(\mathrm{Hz})\end{array}$ & $\begin{array}{c}\text { Razão } \\
6 / \int\end{array}$ \\
\hline \multirow{2}{*}{$\mathrm{B} 1 \mathrm{~F}$} & [6] & 2.306 & 2.199 & 2.313 & 2.382 & 2.291 & 2.303 & \multirow{2}{*}{1,086} \\
\hline & {$\left[\int\right]$} & 2.121 & 2.134 & 2.072 & 2.110 & 2.161 & 2.121 & \\
\hline \multirow{2}{*}{ B2F } & [6] & 2.587 & 2.479 & 2.172 & 2.403 & 2.129 & 2.351 & \multirow{2}{*}{1,044} \\
\hline & {$\left[\int\right]$} & 2.415 & 2.538 & 1.896 & 2.158 & (Obs. 1) & 2.251 & \\
\hline \multirow{2}{*}{ B3M } & [6] & 2.088 & 2.060 & 2.051 & 1.980 & 2.034 & 2.048 & \multirow{2}{*}{1,004} \\
\hline & {$\left[\int\right]$} & 2.015 & 2.082 & 1.997 & 2.065 & 2.042 & 2.040 & \\
\hline \multirow{2}{*}{ B4M } & [6] & 1.806 & 1.874 & 2.096 & 1.777 & 1.888 & 1.856 & \multirow{2}{*}{$\mathbf{0 , 9 7 3 2}$} \\
\hline & {$\left[\int\right]$} & 1.860 & 1.850 & 1.988 & 2.232 & 1.873 & 1.907 & \\
\hline
\end{tabular}

1) Dois registros com dados não consistentes. O cálculo foi efetuado com base nos quatro resultados obtidos.

FONTE: O autor. 


\section{COMENTÁRIOS FINAIS}

Do conjunto de oito consoantes pós-alveolares (quatro fricativas e quatro africadas) que apresentam considerável grau de dificuldade para falantes de português em virtude da distinção feita pelo grau de palatalização, enfocou-se nesse estudo o par de fricativas não vozeadas / 6 / e / $/$, inicialmente abordando duas palavras com grande semelhança estrutural, siewca e szewc. Os recursos estatísticos aplicados sobre os sinais de frequência dos ruídos fricativos - ao todo foram testados dezesseis parâmetros - não se mostraram adequados para discernir de forma genérica as consoantes produzidas por quatro falantes nativos de polonês, dois homens e duas mulheres.

O parâmetro que com robustez permitiu a discriminação das fricativas no par de palavras em questão é o segundo formante na transição para a vogal subsequente $\left(F 2^{t}\right)$, um parâmetro acústico que está relacionado ao tamanho da cavidade posterior ao ponto de articulação no trato vocal. Definiu-se a Razão $6 / \int$ como o quociente entre a média de F2 ${ }^{\mathrm{t}}$ na produção de [ 6 ] e de $\left[\int\right]$; os resultados situam-se pelo menos $21 \%$ acima da unidade, verificando a correlação entre o dado acústico e o dado articulatório nas coletas feitas dos falantes nativos. A aplicação do parâmetro às produções dos estudantes brasileiros mostra uma tendência geral a se situar acima da unidade, ainda que em menor grau, indicando um esforço dos aprendizes para produzir sons distintos para essas duas consoantes.

Passou-se em seguida ao par siekiera / szybkowar. Os falantes nativos mantiveram a tendência de produzir os sons com uma Razão $6 / \int$ pelo menos $12 \%$ superior à unidade; esse valor se refere ao cálculo sobre as médias - para um dos informantes, no entanto, houve intersecção entre as séries referentes a [6 ] e a [ J]. Já os resultados dos estudantes situam-se bastante próximo da unidade, indicando pouca ou nenhuma distinção, com exceção de uma informante, para a qual não houve intersecção nas séries e a Razão $6 / \int$ se situou em 1,086.

Os resultados aqui apresentados confirmam a dificuldade da caracterização das fricativas pós-alveolares que se distinguem pela (não) palatalização e corroboram a direção apontada em diversos textos científicos sobre a consistência do uso do segundo formante na transição para a vogal subsequente como indicativo dessa distinção.

O desconhecimento das palavras a serem pronunciadas pode representar uma dificuldade a mais para estudantes da língua estrangeira no momento de realizar as gravações, sendo portanto aconselhável uma preparação anterior, por meio de textos ou de gravações em que tais vocábulos apareçam, ou então a realização de um trabalho conjunto com o professor da turma. 
O presente estudo pode ter continuidade com mais medições de fricativas seguidas por outras vogais, que incorrerão em outros conjuntos de valores de F2 na transição. Resultados provenientes de outros informantes nativos podem também ser instrutivos, bem como uma comparação dos resultados de estudantes em diferentes pontos de aprofundamento na língua, ou então um acompanhamento de uma turma ao longo de alguns semestres com testes periódicos. Outro campo que pode se revelar frutífero é a produção das fricativas em ambiente pré-consonantal. É possível que nesta circunstância, em que não há uma vogal logo na sequência, algum parâmetro estatístico se revele com potencial de discernimento das consoantes. 


\section{REFERÊNCIAS:}

ASSAF, Beata. Dictionnaire de poche Français-Polonais Polonais-Français. Paris: Larousse, 2007.

BARBOSA, Denize Pozzani de Freitas. Gradientes alofônicos de oclusivas alveolares do português brasileiro em uma situação de contato dialetal. 2011. 112 f. Dissertação (Mestrado em Linguística) - Instituto de Estudos da Linguagem, Universidade Estadual de Campinas, Campinas, 2011.

BARTNICKA, Barbara; SATKIEWICZ, Halina. Gramatyka języka polskiego: Podręcznik dla cudzoziemców. Warszawa: Wiedza Powszechna, 2007.

BOERSMA, Paul. Spectrum help. Manual disponível no programa Praat, no menu de ajuda de análise espectral, na tela em que o mesmo apresenta a curva no domínio da frequência. Data de publicação: 23 nov. 2004.

BOERSMA, Paul; WEENINK, David. Praat - doing phonetics by computer. Programa computacional, versão 5.4.02, de 26 de novembro de 2014. Disponível gratuitamente em <www.praat.org > e em <http://www.fon.hum.uva.nl/praat/>. Acesso em $12 \mathrm{dez} .2014$.

BOERSMA, Paul; WEENINK, David. Praat - doing phonetics by computer. Programa computacional, versão 6.1.16, de 06 de junho de 2020. Disponível gratuitamente em $<$ www.praat.org > e em <http://www.fon.hum.uva.nl/praat/>. Acesso em 18 ago. 2020.

COLLING, I. E. Análise da produção de consoantes fricativas por alunos brasileiros de polonês como língua estrangeira. 71f. Trabalho de Graduação (Bacharelado em Letras - Polonês) - Setor de Ciências Humanas e Letras, Universidade Federal do Paraná, Curitiba, 2014.

DLUGOSZ, Cezary. Dicionário polaco-português português-polaco / Słownik polskoportugalski portugalski-polsko. Porto: Porto Editora, 2009. (Dicionários Acadêmicos.)

DUBIELA, Mateus Renan. A vogal "e" átona final em produções de falantes curitibanos. Trabalho de Graduação (Letras) - Setor de Ciências Humanas e Letras, Universidade Federal do Paraná, Curitiba, 2013.

DUBISZ, Stanisław (Red.). Uniwersalny słownik języka polskiego PWN. Warszawa: Wydawnictwo Naukowe PWN, 2008. 4v. 
HAMANN, Silke. Postalveolar fricatives in slavic languages as retroflexes. In: BAAUW, S.; HUISKES, M.; SCHOORLEMMER, M. (ed.). OTS Yearbook 2002. Utrecht: Utrecht Institute of Linguistics, 2002. p. 105-127. Disponível em: <http://publikationen.ub.unifrankfurt.de/frontdoor/index/index/year/2009/docId/12520>. Acesso em 15 ago. 2020.

IPA (International Phonetic Association). The international phonetic alphabet. 2020. Disponível em: $<$ https://www.internationalphoneticassociation.org/IPAcharts/IPA_chart_ orig/pdfs/IPA_Kiel_2020_full.pdf>. Acesso em 16 ago. 2020.

JASSEM, Wiktor. The acoustic parameters of Polish voiceless fricatives: an analysis of variance. Phonetica, 52, p. 251-258, 1995.

JASSEM, Wiktor. Illustrations of the IPA: Polish. Journal of the International Phonetic Association, v. 33, n. 1, 2003, p. 103-107. Disponível em: <http://www.scribd.com/ doc/32510113/Jassem-2003-Polish-IPA\#scribd>. Acesso em 16 ago. 2020.

LADEFOGED, Peter. A course in phonetics. 4. ed. Boston: Heinle \& Heinle, 2001.

LADEFOGED, Peter. Vowels and consonants: an introduction to the sounds of languages. Malden: Blackwell, 2003 (publ. 2001, reimpr. 2003).

LADEFOGED, Peter ; MADDIESON, Ian. The sounds of world's languages. Oxford: Blackwell, 1996.

LI, F.; EDWARDS, J.; BECKMAN, M. E.: Contrast and covert contrast: The phonetic development of voiceless sibilant fricatives in English and Japanese toddlers. Journal of Phonetics, 37, p. 111-124, 2009. Disponível em: <http://www.ncbi.nlm.nih.gov/pmc/ articles/PMC2723813/pdf/nihms95626.pdf>. Acesso em 16 ago. 2020.

MACIOŁEK, Marcin; TAMBOR, Jolanta. Głoski polskie - Przewodnik fonetyczny dla cudzoziemców i nauczycieli uczących języka polskiego jako obcego. Katowice: Uniwersytet Śląski; Wydawnictwo Gnome, 2012.

MADELSKA, Liliana; SCHWARTZ, Geoffrey. Discovering Polish: a learner's grammar. Kraków: Prolog Szkoła Języków Obcych, 2010.

OLIVEIRA, Flávio Ricardo Medina de. Análise acústica de fricativas e africadas produzidas por japoneses aprendizes de português brasileiro. 2011. 133f. Dissertação (Mestrado em Linguística) - Programa de Pós-Graduação em Letras, Setor de Ciências Humanas,Letras e Artes, Universidade Federal do Paraná, Curitiba, 2011.

SILVA, Adelaide Hercília Pescatori. Língua portuguesa I: fonética e fonologia. Curitiba: IESDE Brasil, 2007. 
WAGNER, Anita ; ERNESTUS, Mirjam ; CUTLER, Anne. Formant transitions in fricative identification: the role of native fricative inventory. Journal of the Acoustical Society of America, v. 120, n. 4, Oct. 2006, p. 2267-2277. Disponível em: $<$ http://repository.ubn.ru.nl/bitstream/handle/2066/42145/42145.pdf? sequence $=1>$. Acesso em 16 ago. 2020.

WELLS, John C. Lingvistikaj aspektoj de Esperanto [Aspectos linguísticos do esperanto]. 2. eld. Rotterdam: Universala Esperanto-Asocio, 1989. 


\section{APÊNDICE A - CENTROIDE, MOMENTOS ESPECTRAIS, DESVIO PADRÃO, CURTOSE, ASSIMETRIA}

Conforme explica o manual do programa Praat, dada uma função distribuição espectral $D(f)$, que expressa a amplitude do sinal em função da frequência $f$, tem-se o centroide (também conhecido como centro de gravidade ou média ponderada, com grandeza de frequência) dado pela expressão (A.1).

$$
f_{c}=\frac{\int_{0}^{\infty} f|D(f)|^{p} \mathrm{~d} f}{\int_{0}^{\infty}|D(f)|^{p} \mathrm{~d} f}
$$

Com expoente $p=1$, a ponderação é feita sobre o módulo da distribuição. Quando a integração é feita com o módulo elevado ao quadrado $(p=2$, valor utilizado por default pelo programa Praat), diz-se que a ponderação é feita sobre a potência do sinal. Boersma (2004) menciona que por vezes se utiliza também $p=1,5$.

Os diferentes momentos espectrais são obtidos por ponderações da diferença entre a frequência $f$ e o centroide $f_{c}$ (sua grandeza é frequência elevada a $n$ ):

$$
\mu_{n}=\frac{\int_{0}^{\infty}\left(f-f_{c}\right)^{n}|D(f)|^{p} \mathrm{~d} f}{\int_{0}^{\infty}|D(f)|^{p} \mathrm{~d} f} .
$$

O segundo momento central, $\mu_{2}$, é denominado variância, e sua raiz quadrada é o desvio padrão $\sigma$, com grandeza de frequência. $O$ momento $\mu_{4}$ é conhecido como curtose absoluta; a curtose ("curtose relativa"), adimensional, é dada por (A.3a). Também a assimetria (A.3b) é adimensional.

$$
\frac{\mu_{4}}{\left(\mu_{2}\right)^{2}}-3 \quad ; \quad \frac{\mu_{3}}{\left(\mu_{2}\right)^{\frac{3}{2}}} \text {. }
$$




\section{APÊNDICE B - SELEÇÃO DE DADOS ACÚSTICOS OBTIDOS A PARTIR DAS PRODUÇÕES DO PAR SZEWC/SIEWCA PELO INFORMANTE P4M}

Apresento nas tabelas B.1 e B.2 alguns dos dados obtidos a partir dos registros do informante P4M. Conforme mencionado quando da apresentação dos resultados, em cada linha são desconsiderados os valores extremos, calculando-se a média com base nos três resultados intermediários. Quando nada é mencionado, utilizou-se o expoente $p=2$. $\mathrm{O}$ símbolo $\sigma$ indica o desvio padrão.

TABELA B.1- PARÂMETROS MEDIDOS NOS REGISTROS DE "SZEWC" -

INFORMANTE P4M.

\begin{tabular}{c|c|c|c|c|c|c}
\hline Parâmetro & \multicolumn{5}{|c}{ Registros } & Média \\
\hline Centroide $(\mathrm{Hz})$ & 3.049 & 3.451 & 3.403 & 2.778 & 2.859 & 3.104 \\
\hline Centroide $[p=1](\mathrm{Hz})$ & 3.814 & 4.194 & 3.995 & 3.799 & 4.072 & $\mathbf{3 . 9 6 0}$ \\
\hline$\sigma(\mathrm{Hz})$ & 1.511 & 1.547 & 1.563 & 1.243 & 1.341 & 1.466 \\
\hline Assimetria & 0,813 & 1,345 & 1,352 & 2,218 & 3,365 & 1,638 \\
\hline Assimetria $[p=1,5]$ & 1,594 & 1,560 & 1,697 & 1,665 & 2,581 & $\mathbf{1 , 6 5 2}$ \\
\hline Curtose & 5,529 & 7,250 & 5,302 & 8,407 & 20,36 & $\mathbf{7 , 0 6 2}$ \\
\hline Curtose $[p=1,5]$ & 7,386 & 5,673 & 6,081 & 4,548 & 9,696 & $\mathbf{6 , 3 8 0}$ \\
\hline Curtose $[p=1]$ & 4,672 & 2,837 & 3,768 & 2,194 & 3,195 & 3,267 \\
\hline F2 $^{\mathrm{t}}(\mathrm{Hz})$ & 1.411 & 1.600 & 1.551 & 1.594 & 1.535 & $\mathbf{1 . 5 6 0}$ \\
\hline
\end{tabular}

FONTE: O autor. 
TABELA B.2 - INFORMANTE P4M: MEDIÇÕES REFERENTES ÀS PRODUÇÕES DE "SIEWCA".

\begin{tabular}{c|c|c|c|c|c|c}
\hline Parâmetro & \multicolumn{5}{|c}{ Registros } & Média \\
\hline Centroide $(\mathrm{Hz})$ & 2.658 & 2.383 & 2.940 & 2.735 & 2.574 & 2.656 \\
\hline Centroide $[p=1](\mathrm{Hz})$ & 3.574 & 3.119 & 3.734 & 3.441 & 3.672 & $\mathbf{3 . 5 6 2}$ \\
\hline$\sigma(\mathrm{Hz})$ & 1.625 & 1.361 & 1.811 & 1.404 & 1.891 & 1.613 \\
\hline Assimetria & 1,075 & 1,070 & 1,008 & 1,409 & 1,611 & 1,185 \\
\hline Assimetria $[p=1,5]$ & 1,306 & 1,040 & 1,258 & 1,373 & 1,468 & $\mathbf{1 , 3 1 2}$ \\
\hline Curtose & 2,392 & 2,473 & 2,251 & 5,046 & 4,148 & $\mathbf{3 , 0 0 4}$ \\
\hline Curtose $[p=1,5]$ & 3,645 & 1,748 & 3,435 & 3,438 & 2,996 & $\mathbf{3 , 2 9 0}$ \\
\hline Curtose $[p=1]$ & 3,265 & 1,540 & 3,102 & 2,040 & 1,776 & 2,306 \\
\hline F2 $^{\mathrm{t}}(\mathrm{Hz})$ & 2.010 & 1.953 & 1.927 & 1.910 & 1.938 & $\mathbf{2 . 0 1 0}$ \\
\hline
\end{tabular}

FONTE: O autor. 